\title{
Population Pharmacokinetics and Safety of Oral Tetra-Arsenic Tetra-Sulfide Formula in Pediatric Acute Promyelocytic Leukemia
}

\author{
Li Zhang, ',* Xin-Mei Yang, 2,* \\ Jing Chen, ${ }^{3}$ Lei Hu, ${ }^{4}$ Fan Yang, \\ Yue Zhou, ${ }^{5}$ Bei-Bei Zhao,' \\ Wei Zhao, (D) ${ }^{2,5} *$ Xiao-Fan Zhu ${ }^{1} *$ \\ 'Department of Pediatric, State Key Laboratory of \\ Experimental Hematology, National Clinical \\ Research Center for Blood Diseases, Institute of \\ Hematology \& Blood Diseases Hospital, Chinese \\ Academy of Medical Sciences \& Peking Union \\ Medical College, Tianjin, People's Republic of \\ China; ${ }^{2}$ Department of Clinical Pharmacy, Clinical \\ Trial Center, The First Affiliated Hospital of \\ Shandong First Medical University \& Shandong \\ Provincial Qianfoshan Hospital, Jinan, People's \\ Republic of China; ${ }^{3}$ Pediatric Hematology \& \\ Oncology, Shanghai Children's Medical Center, \\ Shanghai jiao Tong University School of Medicine, \\ Shanghai, People's Republic of China; ${ }^{4}$ Tianjin \\ Institute of Pharmaceutical Research (TIPR), \\ Tianjin, People's Republic of China; ${ }^{5}$ Department of \\ Clinical Pharmacy, Key Laboratory of Chemical \\ Biology (Ministry of Education), School of \\ Pharmaceutical Sciences, Cheeloo College of \\ Medicine, Shandong University, Jinan, People's \\ Republic of China \\ *These authors contributed equally to this work
}

Correspondence: Xiao-Fan Zhu

Department of Pediatric, State Key Laboratory of Experimental Hematology, National Clinical Research Center for Blood Diseases, Institute of Hematology \& Blood Diseases Hospital, Chinese Academy of

Medical Sciences \& Peking Union Medical College, 288 Nanjing Road, Tianjin, 300020,

People's Republic of China

Tel/Fax +8622 2390900 I

Email xfzhu@ihcams.ac.cn

Wei Zhao

Department of Clinical Pharmacy, School of Pharmaceutical Sciences, Shandong University, No. 44, Wenhua West Road, Jinan, Shandong Province, People's Republic of China

Tel/Fax +86 53I 88383308

Email zhao4wei2@hotmail.com
Background: An oral tetra-arsenic tetra-sulfide $\left(\mathrm{AS}_{4} \mathrm{~S}_{4}\right)$ formula has been recommended as an outpatient post-remission treatment for Chinese adults with acute promyelocytic leukemia (APL) but limited data are available for children. In this exploratory study, we aimed to evaluate the pharmacokinetics and safety of the $\mathrm{AS}_{4} \mathrm{~S}_{4}$ formula in children.

Methods: Eleven newly diagnosed and one relapsed pediatric patient (4-14 years of age) treated with the $\mathrm{AS}_{4} \mathrm{~S}_{4}$ formula were included. Blood samples were collected from 12 children, and drug concentrations were quantified by ICP-MS. Population pharmacokinetic analysis and Monte-Carlo simulation were performed using NONMEM software. Toxic effects were graded according to the NCI-CTCAE, Version 3.

Results: A total of 107 arsenic concentrations $\left(0.1-75.0 \mu \mathrm{g} \mathrm{L}^{-1}\right)$ were used for population pharmacokinetic analysis. The median (range) of estimated weight-normalized CL and volume distribution at steady-state were 45.26 (35.63-82.18) $\mathrm{L} \mathrm{h}^{-1} \mathrm{~kg}^{-1}$ and 230.37 (85.96-495.68) $\mathrm{L} \mathrm{kg}^{-1}$, respectively. No patients discontinued $\mathrm{AS}_{4} \mathrm{~S}_{4}$ treatment owing to adverse events, and there were no drug-related adverse events over grades 3-4. All newly diagnosed APL patients were in MCR with a median follow-up of 28 months (range, 23 to 37 months). Both the estimated 3-year EFS and OS rates were $100 \%$.

Conclusion: The pharmacokinetics and safety oral $\mathrm{AS}_{4} \mathrm{~S}_{4}$ formula was evaluated for the first time in pediatric APL. The pharmacokinetic assessment demonstrated that the dosing regimen of $60 \mathrm{mg} / \mathrm{kg} / \mathrm{d}$ TID resulted in a higher steady-state through concentration in children than that which was achieved in adults. The results of this study indicate that the $\mathrm{AS}_{4} \mathrm{~S}_{4}$ formula is safe in newly diagnosed pediatric APL patients.

Keywords: acute promyelocytic leukemia, Realgar-Indigo Naturalis Formula, pediatric, safety, population pharmacokinetics

\section{Introduction}

The combination of all-trans-retinoic acid (ATRA) and arsenic trioxide (ATO) has become the first-line treatment for patients with acute promyelocytic leukemia (APL). Several large multicenter trials have resulted in complete response in $94-100 \%$ of patients and long-term survival in more than $95 \%$ of patients. ${ }^{1-7}$ However, ATO is administered intravenously and patients must stay in the hospital. In pursuit of high cost-effectiveness and convenience, home-based therapy with oral arsenic could increase compliance with therapy and should be highly recommended in children to improve the long-term efficacy and safety of the treatment. 
Tetra-arsenic tetra-sulfide $\left(\mathrm{AS}_{4} \mathrm{~S}_{4}\right)$ as the only commercially oral arsenic agent was launched in China in 2009. Several clinical trials have shown that the efficacy and safety of oral arsenic $\mathrm{AS}_{4} \mathrm{~S}_{4}$ are similar to ATO in adults and improve the quality of life. ${ }^{8-13}$ Oral $\mathrm{AS}_{4} \mathrm{~S}_{4}$ formula has been recommended as substitute therapy in adults with acute promyelocytic leukemia (APL). ${ }^{8-13}$ Furthermore, an outpatient postremission therapy model had been developed in adults. ${ }^{11,14}$ However, limited information is available for children with APL. ${ }^{15}$ This study aimed to evaluate the pharmacokinetics and safety of $\mathrm{AS}_{4} \mathrm{~S}_{4}$ as consolidation and/or maintenance therapy for children with APL after induction therapy with ATRA and ATO.

\section{Patients and Methods Study Design}

A prospective, open-label study of oral $\mathrm{AS}_{4} \mathrm{~S}_{4}$ formula Realgar-Indigo Naturalis Formula (RIF, Yifan Pharmaceutical Co., Tianchang, China), from July 2016 to July 2019, was conducted at the State Key Laboratory of Experimental Hematology, Institute of Hematology \& Blood Diseases Hospital, Chinese Academy of Medical Sciences and Peking Union Medical College, Tianjin, China. Both non-high-risk and high-risk diagnosed APL children receiving RIF as part of their treatment were enrolled in the study. A genetic diagnosis was established by detecting the PML/RARa fusion gene using polymerase-chain-reaction (PCR) assays. Children age 2 to 18 years with APL in complete remission were eligible for the study. Patients with organ dysfunction (abnormal renal and liver function) were excluded. The enrolled children were required an Eastern Cooperative Oncology Group (ECOG) score of 0. This study was approved by the Ethics Committee of the Institute of Hematology \& Blood Diseases Hospital. Signed informed consent was obtained from the patients' parents or guardians. This trial was conducted in accordance with the Declaration of Helsinki and registered in the Chinese Clinical Trial Registry (ChiCTR-OIC-16010014).

\section{Treatment Protocol and Pharmacokinetic Sampling}

All patients received ATRA $\left(25 \mathrm{mg} / \mathrm{m}^{2} / \mathrm{d}\right.$, days $\left.1-42\right)$ and ATO $(0.15 \mathrm{mg} / \mathrm{kg} / \mathrm{d}$, days $1-28)$ for induction therapy and achieved complete remission. For patients in maintenance therapy, which was designated as regimen A, they received maintenance therapy with RIF $(60 \mathrm{mg} / \mathrm{kg} / \mathrm{d}$, three times daily,
TID) and ATRA after receiving four sequential courses of the following consolidation chemotherapy: idarubicin (IDA) $10 \mathrm{mg} / \mathrm{m}^{2} / \mathrm{d}$ for days $1-3$; ATO $0.15 \mathrm{mg} / \mathrm{kg} / \mathrm{d}$ for days 1-28; and two cycles of daunorubicin (DNR) $45 \mathrm{mg} / \mathrm{m}^{2} / \mathrm{d}$ for days 1-3. For newly diagnosed APL patients in consolidation therapy, which was designated as regimen $\mathrm{B}$, they received also ATRA $\left(25 \mathrm{mg} / \mathrm{m}^{2} /\right.$ d, days $\left.1-42\right)$ and ATO $(0.15 \mathrm{mg} / \mathrm{kg} / \mathrm{d}$, days $1-28)$ as remission induction therapy. After achieving hematologic remission, patients with an initial WBC count less than $10 \times 10^{9} \mathrm{~L}-1$ were treated with consolidation therapy as follows: ATRA $\left(25 \mathrm{mg} / \mathrm{m}^{2} / \mathrm{d}\right.$, days 1-28) and RIF (60 mg/kg/d, days 1-28) for two cycles, then ATRA $\left(25 \mathrm{mg} / \mathrm{m}^{2} / \mathrm{d}\right.$, days $\left.1-21\right)$ and RIF (60 mg/kg/d, days 1-21) for another two cycles. For low-risk patients, RIF and ATRA were sequentially used as a maintenance treatment. The patients with an initial WBC count above $10 \times 10^{9} \mathrm{~L}^{-1}$ were treated with two courses of IDA $\left(8 \mathrm{mg} / \mathrm{m}^{2} / \mathrm{d}\right.$, days $\left.1-3\right)$, ATRA ( $25 \mathrm{mg} / \mathrm{m}^{2} / \mathrm{d}$, days $\left.1-28\right)$, and RIF ( $60 \mathrm{mg} / \mathrm{kg} / \mathrm{d}$, days 1-28). Maintenance therapy for the high-risk patients consisted of five similar cycles. Each cycle for the high-risk patients included ATRA $\left(25 \mathrm{mg} / \mathrm{m}^{2} / \mathrm{d}\right.$, days $\left.1-21,43-63\right)$, RIF (60 mg/kg/d, days 1-21), mercaptopurine (6-MP, $50 \mathrm{mg} /$ $\mathrm{m}^{2} / \mathrm{d}$, day 29-84) and methotrexate (MTX, $25 \mathrm{mg} / \mathrm{m}^{2} / \mathrm{w}$, days 29-84). The regimen A and B group information is shown in Supplementary Figure.

Blood samples for measuring arsenic concentrations were collected before administration and at 1, 2, 4, 6, 7, $8,9,10,16,20,24$ and 28 hours post-administration on day 1. From days 8 to 28 , blood samples were collected once a week before medication. Four blood samples were collected during a 2-week period after cessation of arsenic treatment. Only the samples with validated sampling information were included. Plasma specimens were stored at $4{ }^{\circ} \mathrm{C}$ and analyzed within 2 weeks. The arsenic concentration was analyzed with Agilent 7700xICP-MS (Agilent Technologies, USA) equipped with a pure He octopole reaction system (ORS) was used for total arsenic analysis as reported previously. ${ }^{7}$ The calibration curve ranged from 0.015 to $50 \mu \mathrm{g} \mathrm{L}^{-1}$. The inter- and intra-day coefficients of variation $(\mathrm{CVs})$ of controls were $3.71 \%$ and $4.42 \%$, respectively. The lower limit of detection was $0.015 \mu \mathrm{g} \mathrm{L}$.

\section{Population Pharmacokinetic Modeling of Oral $\mathrm{AS}_{4} \mathrm{~S}_{4}$ Formula}

Pharmacokinetic analysis was performed using the nonlinear mixed-effects modeling software NONMEM V 7.2 (Icon Development Solutions, USA). Pharmacokinetic 
parameter estimates were obtained using the first-order conditional estimation (FOCE) method with interaction. Inter-individual variability of the pharmacokinetic parameters was estimated using an exponential model as previously described. ${ }^{16}$

Covariates of body weight, age, serum creatinine concentration, albumin concentration (ALB), aspartate aminotransferase (AST) and alanine aminotransferase (ALT) were investigated to determine the covariate-parameter relationships using the likelihood ratio test. During the forward selection process of covariate model development, a covariate was included if a statistically significant drop in the objective function value (OFV) (reduction $>3.84$, $\mathrm{p}<0.05, \chi^{2}$ distribution with one degree of freedom) was observed together with a reduction in the variability of the pharmacokinetic parameter. All selected significant covariates were then incorporated simultaneously into a "full" model. Subsequently, the final model was declared after backward elimination of each covariate when the covariate remained statistically significant effect to the pharmacokinetic parameter in the final model $(\Delta \mathrm{OF}>6.635, \mathrm{P}<0.01$, $\chi^{2}$ distribution). ${ }^{16}$ Goodness-of-fit plots included plots of observed (DV) versus either the population prediction (PRED) or the individual prediction (IPRED); conditional weighted residuals (CWRES) over either range in time or PRED were initially used for graphical diagnostic purposes. ${ }^{17}$ The performance and stability of the final model were validated based on graphical and statistical analyses obtained from nonparametric bootstraps $(n=1000)$ and prediction distribution errors (NPDE). ${ }^{17-20}$ One thousand datasets were simulated using the final population model parameters. A QQ-plot and histogram of the NPDE were provided graphically by the NPDE $\mathrm{R}$ package (v1.2). ${ }^{21}$ The NPDE was expected to follow the $\mathrm{N}(0,1)$ distribution.

\section{Safety}

Toxic effects were graded according to the NCI Common Terminology Criteria for Adverse Events, Version 3. Patients underwent a blood routine and electrocardiogram once a week, liver and kidney function were monitored twice per month.

\section{Statistical Analysis}

EFS and OS were estimated using the Kaplan-Meier method, and Log rank tests were used for comparisons. All statistical analyses were performed using SPSS 16.0 software (SPSS, Chicago, IL, USA).

\section{Results}

\section{Study Population}

Eleven newly diagnosed APL patients and one relapsed patient with a median age of 8 (range 4-14) years were included in the present study. The main clinical and biological characteristics of these 12 patients are shown in Table 1. Seven patients were enrolled and treated with oral $\mathrm{AS}_{4} \mathrm{~S}_{4}$ formula RIF in maintenance therapy (regimen $\mathrm{A}$ ), and five patients were enrolled and administered consolidation therapy that included RIF on a schedule of 3 to 4 weeks for 8 months (regimen B). Two (18.2\%) of the 11 newly diagnosed patients who were tested after induction were negative for PML/RARa fusion transcripts. After the first consolidation cycle, $11(100 \%)$ of the patients were negative (Supplementary Figure). All newly diagnosed APL patients were in MCR with a median follow-up of 28 months (range, 23 to 37 months). Both the estimated 3-year EFS and OS rates were 100\%. However, the relapsed patient who began the study relapsed again and gave up further treatment.

Table I Baseline Characteristics in 12 Patients

\begin{tabular}{|c|c|c|c|}
\hline & Number & Mean (SD) & Median (Range) \\
\hline Patients & 12 & & \\
\hline Race & $\begin{array}{c}12 \\
\text { Chinese }\end{array}$ & & \\
\hline AGE (years) & & $7.73(3.169)$ & $8.0(4.0-14.0)$ \\
\hline CW (kg) & & $30.03(14.06)$ & $27(16.0-63.0)$ \\
\hline $\begin{array}{l}\text { CREA }(\mu \mathrm{mol} \\
\left.L^{-1}\right)\end{array}$ & & $32.59(9.56)$ & $32.6($ (I8.4-58.4) \\
\hline ALT $\left(\mathrm{U} \mathrm{L}^{-1}\right)$ & & 20.68 (II.82) & $15.2(9.0-4.4)$ \\
\hline AST $\left(U^{-1}\right)$ & & 27.37 (6.72) & $26.2(17.7-38.0)$ \\
\hline $\operatorname{ALB}\left(\mathrm{g} \mathrm{L}^{-1}\right)$ & & $44.13(2.59)$ & $43.8(40.4-49.6)$ \\
\hline $\mathrm{TP}\left(\mathrm{g} \mathrm{L}^{-1}\right)$ & & $69.52(4.69)$ & $69.9(62.9-77.0)$ \\
\hline TBIL $\left(\mu \mathrm{mol} \mathrm{L}^{-1}\right)$ & & $9.68(3.83)$ & $9.2(5.5-19.9)$ \\
\hline $\operatorname{ALP}\left(\mathrm{U} \mathrm{L}^{-1}\right)$ & & $\begin{array}{l}274.21 \\
(85.34)\end{array}$ & $\begin{array}{c}234.75 \\
(|82.0-4| 0.0)\end{array}$ \\
\hline \multicolumn{4}{|l|}{ RIF treatment } \\
\hline $\begin{array}{l}\text { Dose (mg } \\
\text { dose }^{-1} \text { ) }\end{array}$ & & $\begin{array}{c}588.79 \\
(285.13)\end{array}$ & $540(320-1350)$ \\
\hline
\end{tabular}

Abbreviations: CW, current weight; CREA, serum creatinine concentration; ALT, alanine transaminase concentration; AST, aspartate transaminase concentration; ALB, albumin concentration; TP, total protein; TBIL, total bilirubin; ALP, alkaline phosphatas. 


\section{Population Pharmacokinetic Analysis}

A total of 107 arsenic concentrations were used for PopPK analysis. The arsenic concentrations of the blood samples ranged from 0.1 to $75.0 \mu \mathrm{g} \mathrm{L}^{-1}$. A onecompartment model with first-order elimination fitted the data. The model was parameterized in terms of volume of distribution (V) and clearance (CL) of $\mathrm{AS}_{4} \mathrm{~S}_{4}$. Inter-individual variability was best described by an additive model and was then estimated for $\mathrm{V}$ and CL. A proportional model best described residual variability.

Body weight, age, serum creatinine concentration, ALB, AST and ALT were evaluated as clinically relevant and physiologically plausible covariates. All covariates were screened, selected, then introduced separately into the structural model to identify a set of significant covariates. Body weight brought a significant impact on pharmacokinetic parameters with a decrease in OFV by 13.141 points on CL. No other tested covariate caused further significant improvement of the model. Acceptable goodness-of-fit plots for the developmental PopPK model of the oral $\mathrm{AS}_{4} \mathrm{~S}_{4}$ formula is presented in Figure 1. The predictive values shown in Figure $1 \mathrm{~A}$ and $\mathrm{B}$ demonstrate that this model has no significant bias. No trend in the plots of CWRES versus time or PRED was observed (Figure 1C and D). Besides, the results of bootstrap analysis on the final model revealed that the median parameter estimates were within the $95 \%$ confidence interval, thus indicating that the final model has a good predictive performance and could re-determine the estimates of PopPK parameters (Table 2). The NPDEs are presented in Figure $1 \mathrm{E}$ and F. NPDE distribution and histograms closely resembled the theoretical $\mathrm{N}(0,1)$ distribution and density, indicating a good fit of the model to the individual data. The mean and variance of NPDE were -0.118 and 0.93 , respectively.

Table 2 summarizes the parameter estimates of the final pharmacokinetic model. The median (range) of the estimated weight-normalized CL and volume distribution at steady-state were $45.26(35.63-82.18) \mathrm{L} \mathrm{h}^{-1}$ $\mathrm{kg}^{-1}$ and 230.37 (85.96-495.68) $\mathrm{L} \mathrm{kg}^{-1}$, respectively. The $\mathrm{AUC}_{0-24}$ at steady-state for the evaluated dose regimen ranged from 0.24 to $0.56 \mathrm{mg} \cdot \mathrm{h} \mathrm{L}^{-1}$. When administered orally at $60 \mathrm{mg} / \mathrm{kg} / \mathrm{d}$ TID of RIF, the plasma arsenic concentration was from $0.17 \mu \mathrm{g} \mathrm{L}^{-1}$ to $5.6 \mu \mathrm{g}$ $\mathrm{L}^{-1}$ after 24 hours. The steady-state trough plasma arsenic concentration during the $\mathrm{AS}_{4} \mathrm{~S}_{4}$ formula treatment was 47.43 (range, 25.74-62.97) $\mu \mathrm{g} \mathrm{L}^{-1}$. Monte Carlo simulation showed that the median steady-state Cmin (Css min) were 25.38, 38.17, and $50.66 \mu \mathrm{g} \mathrm{L}^{-1}$ when patients receive RIF with dosing regimens of 30 , 45 , and $60 \mathrm{mg} / \mathrm{kg} / \mathrm{d}$ TID, respectively.

\section{Safety}

RIF-related adverse effects are listed in Table 3. During the RIF treatment, no grade 3-4 liver and kidney adverse events occurred in any of the patients. Two (16.7\%) patients had moderate hepatic toxic effects (increased liver ALT and AST). Three (25.0\%) patients had a transience asymptomatic QTc prolongation on electrocardiography (QTc interval range, 451-458 ms). Other RIF related adverse reactions included anemia (16.7\%) and nausea (8.3\%). All RIF-related side-effects were moderate and reversible after appropriate management was provided.

\section{Discussion}

The PopPK and safety of oral $\mathrm{AS}_{4} \mathrm{~S}_{4}$ formula were evaluated for the first time in Chinese pediatric APL patients. ATRA-ATO was recently shown to have an advantage over ATRA-chemotherapy on APL treatment. ${ }^{1-3}$ The pharmacokinetic assessment demonstrated that the current dosing regimen of $60 \mathrm{mg} / \mathrm{kg} / \mathrm{d}$ TID resulted in a higher steady-state through concentration in children than that which was achieved in adults $\left(24.4 \mu \mathrm{g} \mathrm{L}^{-1}\right.$, range: $\left.11.5-64 \mu \mathrm{g} \mathrm{L}^{-1}\right) .{ }^{9}$ It is also noteworthy that Monte Carlo simulation based on developmental PopPK modeling showed that a median steady-state Cmin (Css min) was $25.38 \mu \mathrm{g} \mathrm{L}^{-1}$ if pediatric patients received RIF $30 \mathrm{mg} / \mathrm{kg} / \mathrm{d}$ TID, which was generally comparable to that on adults receiving RIF at $60 \mathrm{mg} / \mathrm{kg} / \mathrm{d}$ TID. Along with the effectiveness and safety results, the proposed dose could be further used in the following studies in a future study. A dose reduction might be considered appropriate in patients who experience concentration-related adverse reactions. Yang et $\mathrm{al}^{15}$ is ongoingly evaluated a much higher dose of $135 \mathrm{mg} / \mathrm{kg} / \mathrm{d}$ in pediatric APL patients. Obviously, the higher dosage of $\mathrm{AS}_{4} \mathrm{~S}_{4}$ formula is likely unnecessary, as it may not further improve the outcome and a higher cumulative dose may lead to more long-term side-effects, especially in children.

Regarding the safety evaluation, $\mathrm{AS}_{4} \mathrm{~S}_{4}$ formula-related adverse reactions included hepatotoxicity (especially in 
A

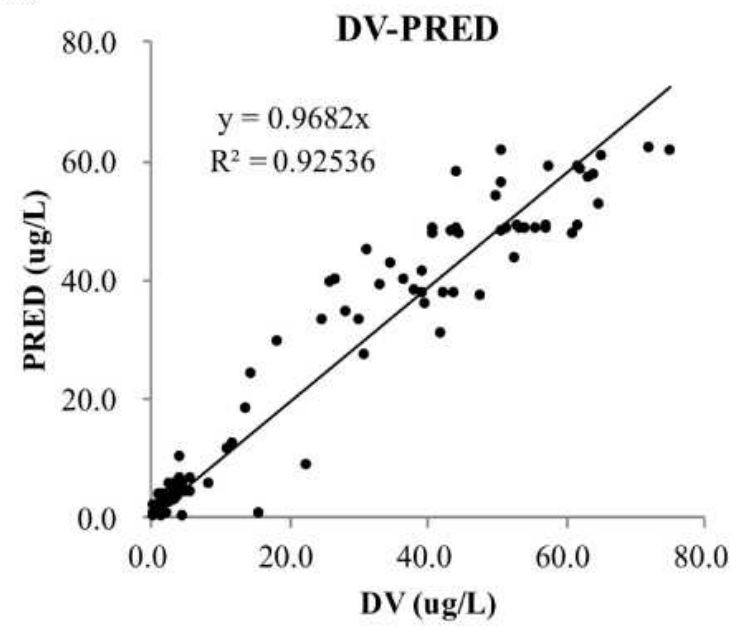

C

\section{TIME-CWRES}

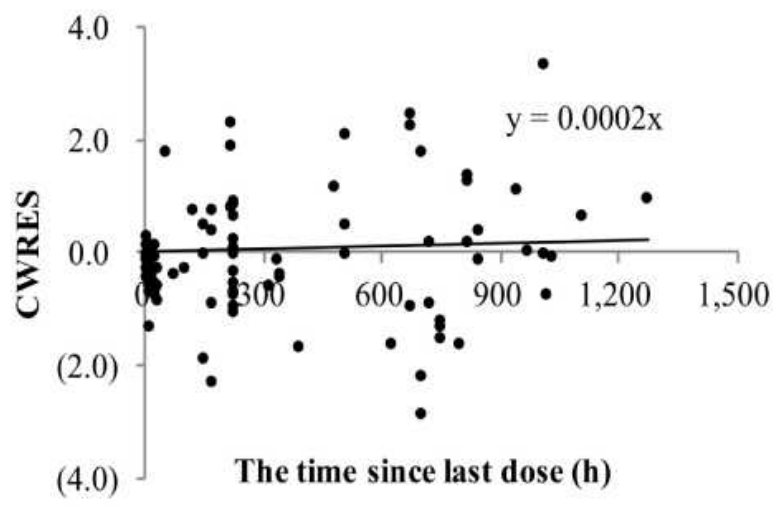

E

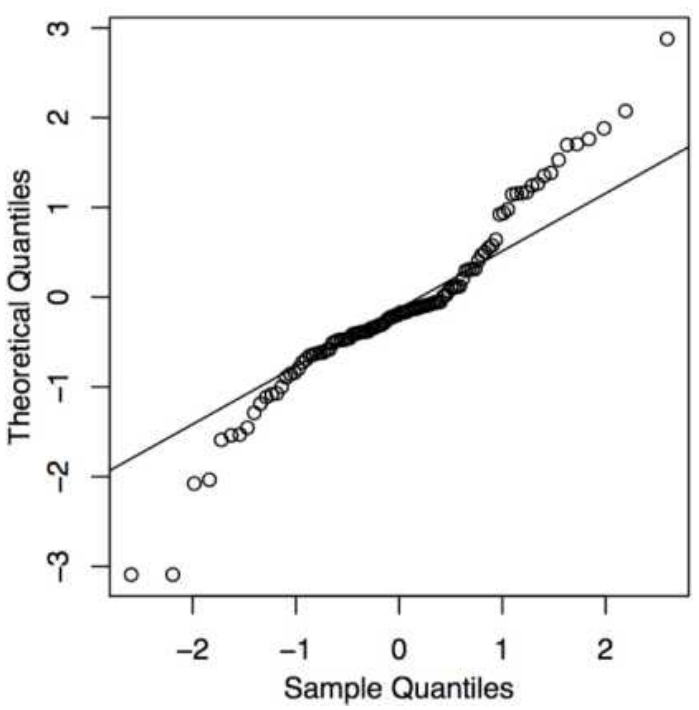

B

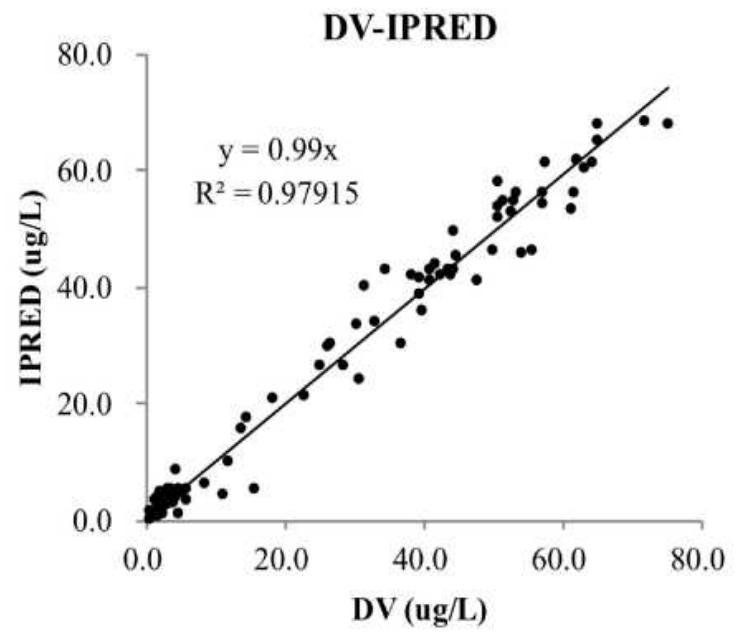

D

\section{PRED-CWRES}

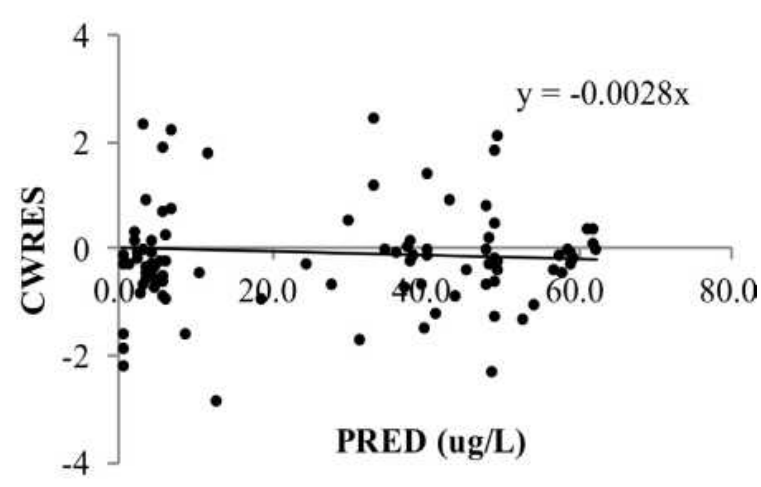

F

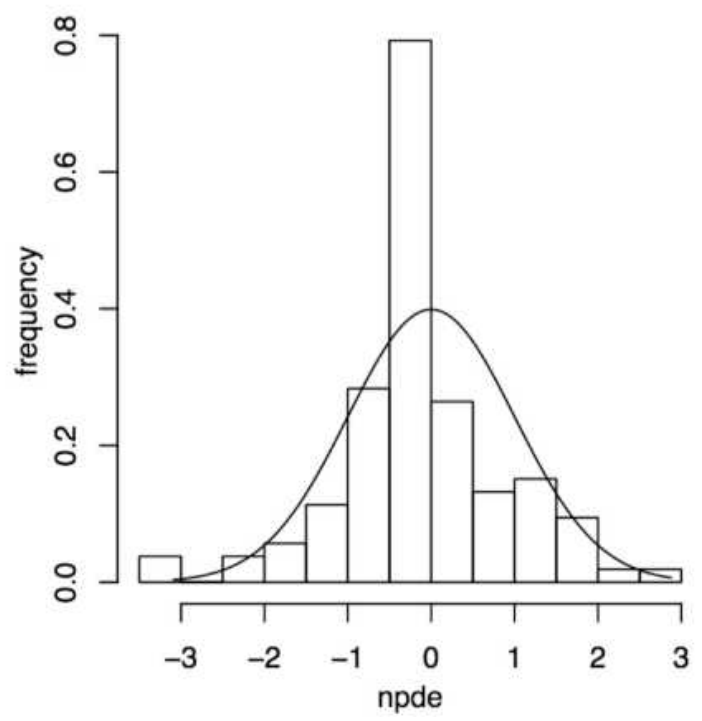

Figure I Diagnostic goodness-of-fit plots for the final population pharmacokinetic model of $\mathrm{AS}_{4} \mathrm{~S}_{4}$ formula. (A) Observed (DV) versus population predicted (PRED) concentrations; (B) DV versus individual predicted (IPRED) concentrations; (C) time versus conditional weighted residuals (CWRES); (D) PRED versus CWRES; and (E) QQ plot of the distribution of the normalized prediction distribution errors (NPDE) versus theoretical N $(0, I)$ distribution; $(F)$ histogram of the distribution of the NPDE, overlaid with the density of the standard Gaussian distribution. 
Table 2 Population Pharmacokinetic Parameters of $\mathrm{AS}_{4} \mathrm{~S}_{4}$ Formula and Bootstrap Results

\begin{tabular}{|c|c|c|c|c|}
\hline \multirow[t]{2}{*}{ Parameters } & \multicolumn{2}{|c|}{ Full Dataset } & \multicolumn{2}{|c|}{ Bootstrap } \\
\hline & $\begin{array}{c}\text { Final } \\
\text { Estimate }\end{array}$ & $\begin{array}{c}\text { RSE } \\
\text { (\%) }\end{array}$ & Median & 5th-95th \\
\hline \multicolumn{5}{|l|}{$\begin{array}{l}\text { Absorption rate } \\
\text { constant }\left(h^{-1}\right) \mathrm{Ka}\end{array}$} \\
\hline \multicolumn{5}{|l|}{$\mathrm{Ka}=\theta_{1} \times \operatorname{EXP}\left(\eta_{1}\right)$} \\
\hline$\theta_{1}$ & 0.013 & 17.3 & 0.013 & $0.0098-0.0180$ \\
\hline \multicolumn{5}{|l|}{$\begin{array}{l}\text { Oral clearance (L } \\
\left.\mathrm{h}^{-1}\right) \mathrm{CL} / \mathrm{F}\end{array}$} \\
\hline \multicolumn{5}{|l|}{$\begin{array}{l}\mathrm{CL} / \mathrm{F}=\theta_{2} \times F_{\mathrm{WT}-} \\
\mathrm{CL} \times \operatorname{EXP}\left(\eta_{2}\right)\end{array}$} \\
\hline$\theta_{2}$ & 1380 & 7.0 & 1350 & $1220-1530$ \\
\hline \multicolumn{5}{|l|}{$\begin{array}{l}\text { Volume of } \\
\text { distribution (L) V/F }\end{array}$} \\
\hline $\mathrm{V} / \mathrm{F}=\theta_{3} \times \operatorname{EXP}\left(\eta_{3}\right)$ & 7080 & 44.6 & 6450 & $3370-13600$ \\
\hline \multicolumn{5}{|l|}{$\theta_{3}$} \\
\hline \multicolumn{5}{|l|}{ 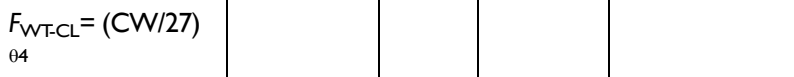 } \\
\hline$\theta_{4}$ & 0.629 & 23.2 & 0.622 & $0.361-0.887$ \\
\hline \multicolumn{5}{|l|}{$\begin{array}{l}\text { Inter-individual } \\
\text { variability (\%) }\end{array}$} \\
\hline Ка & 0.353 & 48.2 & 0.339 & $0.075-0.445$ \\
\hline $\mathrm{CL}$ & 0.167 & 39.3 & 0.139 & $0.078-0.196$ \\
\hline V & 0.787 & 52.6 & 0.781 & $0.023-1.148$ \\
\hline $\begin{array}{l}\text { Residual } \\
\text { variability (\%) }\end{array}$ & 3.619 & 31.9 & 3.688 & $2.747-4.609$ \\
\hline
\end{tabular}

Notes: $\theta_{1}$, typical value of $\mathrm{Ka} ; \theta_{2}$, typical value of oral clearance; $\theta_{3}$, typical value of volume of distribution; $\theta_{4}$, typical value of exponent for body weight effect on $C L$; $F_{\text {WT-CL, }}$ effect of body weight on CL. terms of an increase in liver enzymes), diarrhea and prolongation of the QTc interval. When $\mathrm{AS}_{4} \mathrm{~S}_{4}$ formula was used as a monotherapy, the rate of hepatotoxicity occurred in $7.8-10 \%$ in adults. ${ }^{22,23}$ After combining $\mathrm{AS}_{4} \mathrm{~S}_{4}$ formula with ATRA, the rate of hepatotoxicity increased to about $60 \% .{ }^{9,11}$ All incidences of hepatotoxicity were resolved with a decrease or temporary discontinuation of arsenic and-/or ATRA. When $\mathrm{AS}_{4} \mathrm{~S}_{4}$ formula was used, diarrhea occurred in $7.7-15 \%$ in adults. ${ }^{11,22,23}$. A prolonged QTc interval was not a common side effect of $\mathrm{AS}_{4} \mathrm{~S}_{4}$ formula at the dose of $60 \mathrm{mg} / \mathrm{kg} / \mathrm{d}$ in adults. ${ }^{8}$ Although mild QTc prolongation was found in three patients without any symptoms of arrhythmia, QTe prolongation did not occur afterward during the continued $\mathrm{AS}_{4} \mathrm{~S}_{4}$ formula-therapy; therefore, QTc prolongation was not related to $\mathrm{AS}_{4} \mathrm{~S}_{4}$ formula-therapy. Diarrhea and hepatotoxicity were less common in children than in adults.

The oral $\mathrm{AS}_{4} \mathrm{~S}_{4}$ formula had been proved highly effective in the treatment of adult APL. ${ }^{8-12}$ Zhu et al demonstrated that in adult APL patients, a first-line therapy that included both ATRA and $\mathrm{AS}_{4} \mathrm{~S}_{4}$ formula was safe and effective. ${ }^{8-12}$ The APL07 trial showed that the estimated 7-year cumulative incidences of relapse (CIRs) and event-free survival (EFS) and OS rates were similar between the $\mathrm{AS}_{4} \mathrm{~S}_{4}$ formula and ATO groups in both low- and high-risk APL patients. In our present study, the efficacy results supported the findings in adults. No newly diagnosed patients relapsed. The EFS and OS at 3 years were $100 \%$ with a median follow-up of 28 months. Of note, the patient who had relapsed prior to this study relapsed again during the $\mathrm{AS}_{4} \mathrm{~S}_{4}$ formula and ATRA treatment.

A limitation of this study was the small number of patients and the short length of the follow-up period.

Table 3 Incidence of All Non-Haematological and Haematological Toxic Effects During $\mathrm{AS}_{4} \mathrm{~S}_{4}$ Formula Treatment in 12 Patients

\begin{tabular}{|l|l|l|l|l|l|}
\hline Toxicity Sites & Grade I & Grade 2 & Grade 3 & Grade 4 & Total \\
\hline Nausea & $I$ & 0 & 0 & 0 & I (8.3\%) \\
Vomiting & 0 & 0 & 0 & 0 & 0 \\
Neutropenia with fever & 0 & 0 & 0 & 0 & 0 \\
Anaemia & $I$ & 1 & 0 & 0 & $2(16.7 \%)$ \\
Thrombocytopenia & 0 & 0 & 0 & 0 & 0 \\
Prolonged QTc interval & 3 & 0 & 0 & 0 & 0 \\
Infection & 0 & 2 & 0 & 0 & $2(16.7 \%)$ \\
Increased liver ALT or AST concentrations & 0 & 0 & 0 & 0 \\
Hyperbilirubinemia & 2 & 0 & & 0 \\
Raised creatinine & 0 & & & 0 \\
\hline
\end{tabular}


However, this study provided preliminary PK and safety data in children. Thus, a Phase $2 / 3$ trial with a long term follow-up period has been initiated in China, and patient recruitment has begun.

\section{Conclusion}

The pharmacokinetics of $\mathrm{AS}_{4} \mathrm{~S}_{4}$ formula $(60 \mathrm{mg} / \mathrm{kg} / \mathrm{d}$ TID) used for children was evaluated in this exploratory study. The PopPK analysis revealed that body weight had a significant impact on oral $\mathrm{AS}_{4} \mathrm{~S}_{4}$ formula pharmacokinetics. The results of this study supported the rational use of $\mathrm{AS}_{4} \mathrm{~S}_{4}$ formula in newly diagnosed pediatric APL patients.

\section{Data Sharing Statement}

The raw data supporting the conclusions of this article will be made available by the authors, without undue reservation, to any qualified researcher. The data can be shared by emailing requests to the corresponding author Prof.Dr. Wei Zhao or Prof.Dr. Xiao-Fan Zhu.

\section{Ethics Approval}

All procedures performed in studies involving human participants were approved by the Ethics Committee of the Institute of Hematology \& Blood Diseases Hospital and with the 1964 Helsinki declaration and its later amendments or comparable ethical standards.

\section{Consent to Participate}

Signed informed consent was obtained from the patients' parents or guardians.

\section{Clinical Trial Registry}

This trial was registered in the Chinese Clinical Trial Registry (ChiCTR-OIC-16010014).

\section{Acknowledgments}

We thank all of the patients who participated in this study and all of the participants and research staff in our hospital. We thank the AIYOU and SHENHUA foundations for their financial support for our study of leukemia in children.

\section{Author Contributions}

All authors made a significant contribution to the work reported, whether that is in the conception, study design, execution, acquisition of data, analysis and interpretation, or in all these areas; took part in drafting, revising or critically reviewing the article; gave final approval of the version to be published; have agreed on the journal to which the article has been submitted; and agree to be accountable for all aspects of the work.

\section{Funding}

This work was supported in China by the National Natural Science Foundation of China (81870131), National Science and Technology Major Project (2017ZX09304024, 2017ZX09304029-002), Young Taishan Scholars Program of Shandong Province and Tianjin Municipal Science and Technology Commission Grant (15ZXLCSY00010).

\section{Disclosure}

Li Zhang, Xin-Mei Yang, Jing Chen, Lei Hu, Fan Yang, Yue Zhou, Bei-Bei Zhao, Wei Zhao and Xiao-Fan Zhu declare that they have no conflicts of interest relevant to this article to disclose.

\section{References}

1. Lo-Coco F, Avvisati G, Vignetti M, et al. Retinoic acid and arsenic trioxide for acute promyelocytic leukemia. $N$ Engl J Med. 2013;369 (2):111-121. doi:10.1056/NEJMoa1300874

2. Burnett AK, Russell NH, Hills RK, et al. Arsenic trioxide and all-trans retinoic acid treatment for acute promyelocytic leukaemia in all risk groups (AML17): results of a randomised, controlled, phase 3 trial. Lancet Oncol. 2015;16(13):1295-1305. doi:10.1016/ S1470-2045(15)00193-X

3. Iland HJ, Collins M, Bradstock K. Use of arsenic trioxide in remission induction and consolidation therapy for acute promyelocytic leukaemia in the Australasian Leukaemia and Lymphoma Group (ALLG) APML4 study: a non-randomised phase 2 trial. Lancet Haematol. 2015;2(9): e357-366. doi:10.1016/S2352-3026(15)00115-5

4. Kutny MA, Alonzo TA, Gerbing RB, et al. Arsenic trioxide consolidation allows anthracycline dose reduction for pediatric patients with acute promyelocytic leukemia: report from the children's oncology group phase III historically controlled trial AAML0631. J Clin Oncol. 2017;35(26):3021-3029. doi:10.1200/JCO.2016.71.6183

5. Kutny MA, Gregory J, Feusner JH. Treatment of paediatric APL: how does the therapeutic approach differ from adults? Best Pract Res Clin Haematol. 2014;27(1):69-78. doi:10.1016/j.beha.2014.04.007

6. Abla O, Kutny MA, Testi AM, et al. Management of relapsed and refractory childhood acute promyelocytic leukaemia: recommendations from an international expert panel. Br J Haematol. 2016;175 (4):588-601. doi:10.1111/bjh.14313

7. Zhang L, Zou Y, Chen Y, et al. Role of cytarabine in paediatric acute promyelocytic leukemia treated with the combination of all-trans retinoic acid and arsenic trioxide: a randomized controlled trial. Bmc Cancer. 2018;18(1):374. doi:10.1186/s12885-018-4280-2

8. Zhu HH, Hu J, Lo-Coco Fet al.The simpler the better: oral arsenic for acute promyelocytic leukemia. Blood. 2019;134(7):597-605. doi:10.1182/blood.2019000760

9. Zhu HH, Wu DP, Jin J, et al. Oral tetra-arsenic tetra-sulfide formula versus intravenous arsenic trioxide as first-line treatment of acute promyelocytic leukemia: a multicenter randomized controlled trial. J Clin Oncol. 2013;31(33):4215-4221. doi:10.1200/JCO.2013.48.8312

10. Zhu HH, Wu DP, Jin J, et al. Long-term survival of acute promyelocytic leukaemia patients treated with arsenic and retinoic acid. $\mathrm{Br}$ J Haematol. 2016;174(5):820-822. doi:10.1111/bjh.13809 
11. Zhu HH, Wu DP, Du X, et al. Oral arsenic plus retinoic acid versus intravenous arsenic plus retinoic acid for non-high-risk acute promyelocytic leukaemia: a non-inferiority, randomised phase 3 trial. Lancet Oncol. 2018;19(7):871-879. doi:10.1016/S1470-2045(18) 30295-X

12. Zhu HH, Liu YR, Jia JS, et al. Oral arsenic and all-trans retinoic acid for high-risk acute promyelocytic leukemia. Blood. 2018;131 (26):2987-2989. doi:10.1182/blood-2018-02-834051

13. Zhu $\mathrm{HH}, \mathrm{Hu}$ J, Gu XF. Arsenic as traditional Chinese medicine provides new hope for overcoming high treatment costs of acute promyelocytic leukemia. J Global Oncol. 2016;2(6):442-443. doi:10.1200/JGO.2016.005405

14. Chinese Society of Hematology, Chinese Medical Association, Chinese Medical Doctor Association. Chinese guidelines for diagnosis and treatment of acute promyelocytic leukemia (2018). Chin $J$ Hematol. 2018;39(3):179-183. doi:10.3760/cma.j.issn.02532727.2018.03.002

15. Yang MH, Wan WQ, Luo JS, et al. Multicenter randomized trial of arsenic trioxide and Realgar-Indigo naturalis formula in pediatric patients with acute promyelocytic leukemia: interim results of the SCCLG-APL clinical study. Am J Hematol. 2018;93(12):1467-1473. doi:10.1002/ajh.25271

16. Zhao W, Hill H, Le Guellec C, et al. Population pharmacokinetics of ciprofloxacin in neonates and young infants less than three months of age. Antimicrob Agents Chemother. 2014;58(11):6572-6580. doi:10.1128/AAC.03568-14

17. Hooker AC, Staatz CE, Karlsson MO. Conditional weighted residuals (CWRES): a model diagnostic for the FOCE method. Pharm Res. 2007;24(12):2187-2197. doi:10.1007/s11095-007-9361-x
18. Lindbom L, Ribbing J, Jonsson EN. Perl-speaks-NONMEM (PsN)a Perl module for NONMEM related programming. Comput Methods Programs Biomed. 2004;75(2):85-94. doi:10.1016/j.cmpb. 2003.11.003

19. Brendel K, CometsE, Laffont C, et al. Metrics for external model evaluation with an application to the population pharmacokinetics of gliclazide. Pharm Res. 2006;23(9):2036-2049. doi:10.1007/s11095006-9067-5

20. Bergstrand M, Hooker AC, WallinJE, et al. Prediction-corrected visual predictive checks for diagnosing nonlinear mixed-effects models. AAPS J. 2011;13(2):143-151. doi:10.1208/s12248-0119255-z

21. Comets E, Brendel K, Mentré F. Computing normalised prediction distribution errors to evaluate nonlinear mixed-effect models: the npde add-on package for R. Comput Methods Programs Biomed. 2008;90(2):154-166. doi:10.1016/j.cmpb.2007.12.002

22. Sun F, Chen NN, Cheng YB. Compound realgar and natural indigo tablets in treatment of acute promyelocytic leukemia: a summary of experience in 204 cases. Zhong Xi Yi Jie He Xue Bao. 2008;6 (6):639-642. doi:10.3736/jcim20080618

23. The cooperation group of phase II: clinical trial of compound Huangdai tablet, Qian LS, Zhao YZ. phase II clinical trial of compound Huangdai tablet in newly diagnosed acute promyelocytic leukemia. Chin J Hematol. 2006;27(12):801-804. doi:10.3760/cma. j.issn.0253-2727.2006.12.003

\section{Publish your work in this journal}

Drug Design, Development and Therapy is an international, peerreviewed open-access journal that spans the spectrum of drug design and development through to clinical applications. Clinical outcomes, patient safety, and programs for the development and effective, safe, and sustained use of medicines are a feature of the journal, which has also been accepted for indexing on PubMed Central. The manuscript management system is completely online and includes a very quick and fair peer-review system, which is all easy to use. Visit http://www. dovepress.com/testimonials.php to read real quotes from published authors. 